\title{
ADSORPTION OF COOMASSIE BRILLIANT BLUE R-250 DYE ONTO NOVEL ACTIVATED CARBON PREPARED FROM NIGELLA SATIVA L. WASTE: EQUILIBRIUM, KINETICS AND THERMODYNAMICS RUNNING TITLE: ADSORPTION OF BRILLIANT BLUE DYE ONTO NIGELLA SATIVA L. WASTE ACTIVATED CARBON
}

\author{
NOUR T. ABDEL-GHANI', GHADIR A. EL-CHAGHABY ${ }^{2 *}$, \\ EL-SHAIMAA A. RAWASH² AND EDER C. LIMA \\ ${ }^{1}$ Chemistry Department - Faculty of Sciences - Cairo University - Egypt \\ ${ }^{2}$ RCFF-Agricultural research Center - Giza - Egypt \\ ${ }^{3}$ Institute of Chemistry, Federal University of Rio Grande do Sul (UFRGS), Av. Bento Gonçalves, 9500, Porto Alegre, RS, Brazil
}

\begin{abstract}
In this paper a novel adsorbent was prepared from Nigella sativa L. waste and used for the removal of Coomassie Brilliant Blue dye from wastewater. The preparation of Nigella sativa waste carbon (NSWC) was achieved by adding concentrated sulfuric acid to the precursor material at an impregnation ratio (1: 1) and the mixture was left overnight. The resulting material was washed with sodium bicarbonates and finally oven dried. The kinetics of coomassie brilliant blue adsorption onto NSWC was investigated by three kinetic models. The pseudo-second order model $\left(\mathrm{R}^{2}=0.99\right)$ was the best model fitted the experimental data. The equilibrium results revealed that Freundlich model was the best isotherm model fitted $\left(\mathrm{R}^{2}=0.994\right)$. Also the value of the Freundlich exponent ( $\left.\mathrm{n}\right)$ was found to be 1.174 suggesting the favorable dye adsorption onto NSWC. The thermodynamics results indicated negative values of $\Delta \mathrm{G}$ proving the spontaneous nature of Brilliant Blue dye adsorption on NSWC. The exothermic nature of the adsorption was also confirmed by the negative value of change in enthalpy $\Delta \mathrm{H}^{\circ}$. Also, the negative value of the activation entropy $\Delta \mathrm{S}^{\circ}$ demonstrates the decreased randomness at the solid-solution interface during adsorption. The present study results suggest the possible use of a waste such as Nigella sativa L. waste as a precursor for the development of a new cheap and efficient adsorbent that could be used in dyes removal from wastewater.
\end{abstract}

Keywords: Adsorption; coomassie brilliant blue dye; chemical activation; mechanism; Nigella sativa L. waste.

\section{INTRODUCTION}

In the recent years, adsorption has picked a significant importance as one of the low-cost and high effective techniques for water treatment. Several materials have been studied and were successfully used as adsorbents for the removal of water pollutants. Among the different types of adsorbents, activated carbon (AC) remains the most widely used adsorbents in industry for environmental applications ${ }^{1}$. Activated carbons are carbons of highly porous structure, large surface area and high adsorption capacity. Their surface and structural properties give them a wide application range for the removal of organic and inorganic pollutants from polluted water ${ }^{2}$.

According to ${ }^{3}$, any cheap material with a high carbon content and low inorganics can be used as a raw material for the production of activated carbon $^{3}$. Nowadays several researchers investigate the use of agricultural byproducts for the development of activated carbon which has both economic and environmental impacts as it converts unwanted, low-value agricultural waste to a useful high-value adsorbent ${ }^{4}$.

The activation process could be either physical or chemical and sometimes both processes are involved in the preparation of activated carbon. The physical activation involves carbonization of a carbonaceous materials followed by activation of the resulting char in the presence of activating agents such as $\mathrm{CO}_{2}$ or steam ${ }^{5}$. On the other hand, chemical activation is a single step method involving the use of a chemical activating agent such as $\mathrm{ZnCl}_{2}, \mathrm{KOH}, \mathrm{H}_{2} \mathrm{SO}_{4}$, etc. The advantage of the chemical activation is that it takes place at shorter time than those used in physical activation as well as high yield and high surface area of the produced activated carbons ${ }^{6}$.

Dyes represent a major class of organic pollutants present in wastewater. Synthetic dyes are extensively used in the textile industry, paper printing, color photography, pharmaceutical, leather, cosmetics, plastic, and other industries. The discharge of industrial wastewater containing dyes is considered as one of the highest environmental problems. The presence of even very low concentrations of dyes in water reduces light penetration through the water surface, precluding photosynthesis of the aqueous flora. Many of these dyes are carcinogenic, mutagenic, and teratogenic and also toxic to human beings, fish species and microorganisms ${ }^{7}$. Therefore, the removal of dyes from wastewater effluents is of great concern. Coomassie Brilliant Blue R-250 (CBB) dye, one of the most important synthetic dyes in the textile industry which represents an important class of toxic and recalcitrant organopollutants ${ }^{8}$. Several methods have been proposed for dyes removal from wastewater. Amongst these methods, adsorption is the procedure of choice and gives the best results as it can be used to remove different types of coloring materials 9 .

Nigella sativa L. is a flowering plant growing in Egypt and other countries. The plant's oil has been used long time for its many therapeutic applications. The production of Nigella sativa L. oil is increasing and hence there is a huge amount of Nigella sativa waste that is produced. The aim of the present work is to produce a porous activated carbon from a locally available waste (Nigella sativa $\mathrm{L}$. waste) and its ability to remove brilliant blue dye from wastewater will be assessed. The activated carbon produced will be characterized by different techniques to investigate its properties. Also, kinetic and isothermal studies will be applied to investigate the nature of adsorption process.

\section{MATERIAL AND METHOD}

Nigella sativa waste used as precursor for the preparation of activated carbon was obtained from EL-Baraka factory for natural oils (FBS), coomassie brilliant blue R-250 $\left(\mathrm{C}_{45} \mathrm{H}_{44} \mathrm{~N}_{3} \mathrm{NaO}_{7} \mathrm{~S}_{2}\right)$ and other chemicals used in this work were all supplied by Sigma-Aldrich.

Nigella sativa waste (used as precursor) was washed by n-Hexane with shaking at $200 \mathrm{rpm}$ in water bath at $50^{\circ} \mathrm{C}$ to remove any oil, and then washed by double deionized water then oven dried at $100^{\circ} \mathrm{C}$ until reaching constant weight. The precursor was soaked in concentrated $\mathrm{H}_{2} \mathrm{SO}_{4}$ (purity:98\%) with impregnation ratio $(1: 1) \mathrm{w} / \mathrm{w}^{10}$. The mixture was then left overnight. Then the mixture was washed with sodium bicarbonates $\mathrm{NaHCO}$ till neutral $\mathrm{pH}$ and oven dried at $105^{\circ} \mathrm{C}$ until reaching constant weight. The activation process was done as previously reported by ${ }^{11}$ with some modifications. The adsorbent produced from Nigella sativa was named Nigella sativa waste carbon (NSWC).

The surface morphology of NSWC was identified by scanning electron microscopy technique using a JSM-6390LV (JEOL Ltd, Japan) with a $3 \mathrm{kV}$ accelerating voltage was used to characterize the morphology of the sample which was dried overnight at approximately $105^{\circ} \mathrm{C}$ under vacuum before SEM analysis.

The functional surface groups on the NSWC were studied using an FT-IR (AVATAR $370 \mathrm{Csl}$, Thermo Nicolet Co., USA) at a resolution $4 \mathrm{~cm}^{-1}$ over the range of $500-4000 \mathrm{~cm}^{-1}$, the sample was introduced as $\mathrm{KBr}$ pellet.

$1 \mathrm{~g}$ of Coomassie Brilliant Blue R-250 dye (CBB) (C.I. number $42660)$ powder was dissolved in $1000 \mathrm{~mL}$ of deionized water to prepare the concentration of $1 \mathrm{~g} / \mathrm{L} \mathrm{CBB}$ dye solution. Solution of different initial concentrations $(10,25,50$, and $100 \mathrm{mg} / \mathrm{L})$ were prepared by dilution process of initial stock in deionized water.

Double-beam UV-visible spectrophotometer (Model Shimadzu UV-1800, 
Japan) was used to measure the concentration of the CBB dye. The maximum wavelength of the $\mathrm{CBB}$ was determined as $551 \mathrm{~nm}$. Calibration curve for CBB dye concentration was first plotted with $\left(\mathrm{R}^{2}=0.99\right)$ to assure linearity over the studied concentration range used in this work.

Batch equilibrium experiments were carried out at different contact time, initial dye concentration and temperature. A series of $100 \mathrm{ml}$ capped tubes were used. At the beginning of each experiment runs: each tube was filled with $50 \mathrm{ml}$ of dye solution and NSWC was added into different tubes. The tubes were shaken in a shaking water bath at $100 \mathrm{rpm}$ and at the end of each run the adsorbent was separated from the solution by centrifugation.

The adsorption capacity q (mg/g) was calculated by equation (1)

$$
\mathrm{q}=\frac{(\mathrm{Co}-\mathrm{Ci}) \mathrm{V}}{\mathrm{W}}
$$

Where $\mathrm{C}_{\mathrm{o}}$ and $\mathrm{C}_{\mathrm{i}}(\mathrm{mg} / \mathrm{l})$ are the initial and equilibrium concentrations of CBB dye, respectively.V (1) is the volume of the solution and $\mathrm{W}(\mathrm{g})$ is the mass of activated carbon used.

Dye concentrations were determined at $551 \mathrm{~nm}$ wavelength using a UVvisible Spectrophotometer.

The effect of contact time on dye removal by NSWC was studied by using $50 \mathrm{ml}$ of CBB dye solution with initial concentration $25 \mathrm{mg} / \mathrm{L}$. The amount of

Table 1: Equilibrium models' equations

\begin{tabular}{|c|c|c|}
\hline Model & Equation & Parameters \\
\hline Langmuir $^{3}$ & $\begin{array}{c}\mathrm{C}_{\mathrm{e}} / \mathrm{qe}=1 / \mathrm{b} \mathrm{q}_{\max }+ \\
\mathrm{Ceq} / \mathrm{q}_{\max }\end{array}$ & $\begin{array}{l}\mathrm{q}_{\mathrm{e}} \text { is the amount of dye adsorbed per unit mass of adsorbent }(\mathrm{mg} / \mathrm{g}) \\
\mathrm{b} \text { is the Langmuir constant related to the adsorption capacity }(\mathrm{L} / \mathrm{g}) \\
\mathrm{C}_{\mathrm{e}} \text { is the concentration of adsorbate in the solution at equilibrium }(\mathrm{mg} / \mathrm{L}) \\
\mathrm{q}_{\mathrm{m}} \text { is the maximum uptake per unit mass of carbon }(\mathrm{mg} / \mathrm{g}) \text {. }\end{array}$ \\
\hline Freundlich ${ }^{12}$ & $\begin{aligned} \log \mathrm{q}_{\mathrm{e}} & =\log \mathrm{K}_{\mathrm{f}}+(1 / \mathrm{n}) \\
& \log \mathrm{C}_{\mathrm{e}}\end{aligned}$ & $\begin{array}{l}\mathrm{C}_{e} \text { and have the same meaning as in the Langmuir isotherm } \\
\mathrm{k}_{\mathrm{f}} \text { is the Freundlich constant. } \\
\mathrm{n} \text { is the empirical parameter representing theenergetic heterogeneity of the adsorption sites } \\
\text { (dimensionless) }\end{array}$ \\
\hline Temkin ${ }^{12}$ & $\mathrm{q}_{e}=\mathrm{B}_{T} \operatorname{In} A_{T}+B_{T} \operatorname{InC} \mathrm{C}_{e}$ & $\begin{array}{l}\mathrm{C}_{e} \text { and } \mathrm{q}_{\mathrm{e}} \text { have the same meaning as in the Langmuir isotherm } \\
\mathrm{B}_{\mathrm{T}} \text { is related to the heat of adsorption }(\mathrm{L} / \mathrm{g}) \\
\mathrm{A}_{\mathrm{T}} \text { is the dimensionless Temkin isotherm constant }\end{array}$ \\
\hline
\end{tabular}

Table 2: Kinetic models' equations.

\begin{tabular}{|c|c|c|}
\hline Model & Equation & Parameters \\
\hline Pseudo first-order ${ }^{13}$ & $\ln \left(\mathrm{q}_{\mathrm{e}}-\mathrm{q}_{\mathrm{t}}\right)=\ln \mathrm{q}_{\mathrm{e}}-\mathrm{K}_{1} \mathrm{t}$ & $\begin{array}{l}\text { qe is the amount of adsorbate adsorbed at equilibrium, }(\mathrm{mg} / \mathrm{g}), \mathrm{qt} \text { is the amount of } \\
\text { solute adsorb per unit weight of adsorbent at time, }(\mathrm{mg} / \mathrm{g}), \mathrm{k} 1 \text { is the rate constant of } \\
\text { pseudo-first order sorption }((\mathrm{gm} / \mathrm{mg} \mathrm{min})\end{array}$ \\
\hline pseudo second-order ${ }^{14} \mathrm{t}$ & $\mathrm{t} / \mathrm{q}=1 / \mathrm{K}_{2} \mathrm{q}_{\mathrm{e}}^{2}+\mathrm{t} / \mathrm{q}_{\mathrm{e}}$ & $\begin{array}{l}\text { qt and qe have the same meaning as in the pseudo-first order model and } \mathrm{k} 2 \text { is the rate constant } \\
\text { of second-order model }(\mathrm{g} /(\mathrm{mg} \mathrm{min}))\end{array}$ \\
\hline Elovich's Model ${ }^{12}$ & $\begin{array}{l}\mathrm{q}_{\mathrm{t}}=(1 / \beta) \ln (\alpha \beta)+ \\
\quad(1 / \beta) \ln (\mathrm{t})\end{array}$ & $\begin{array}{l}\alpha \text { is the initial adsorption rate }(\mathrm{mg} / \mathrm{gmin}) \text {, and the parameter } 1 / \beta(\mathrm{mg} / \mathrm{g}) \text { value is reflected the } \\
\text { number of sites available for adsorption }\end{array}$ \\
\hline Intra-particle diffusion model ${ }^{15}$ & $\mathrm{q}_{t}=K_{i d} \mathrm{t}^{1 / 2}+\mathrm{C}_{\mathrm{i}}$ & $\begin{array}{l}K_{i d} \text { is the slope which refer to the intra-particle diffusion rate constant }(\mathrm{mg} / \mathrm{gmin}) \cdot \operatorname{and} \mathrm{C}_{\mathrm{i}}(\mathrm{mg} / \mathrm{g}) \\
\text { is the intercept which is a constant related to the thickness of the boundary layer }\end{array}$ \\
\hline
\end{tabular}

adsorbent that was added into each flask was fixed at $0.5 \mathrm{~g}$. The flasks were placed in a shaking water bath at constant temperature of $35^{\circ} \mathrm{C}$, with shaking speed of $120 \mathrm{rpm}$. The contact time was varied from 30 to $150 \mathrm{~min}$. until equilibrium was reached.

For the pre-determined equilibrium time a $50 \mathrm{ml}$ of CBB dye solution with different initial concentrations of $10,25,50$, and $100 \mathrm{mg} / \mathrm{L}$ were prepared. The amount of adsorbent that was added into each flask was fixed at $0.5 \mathrm{~g}$. The flasks were placed in a shaking water bath at constant temperature of $35^{\circ} \mathrm{C}$, with shaking speed of $120 \mathrm{rpm}$.

The effect of solution temperature on the adsorption thermodynamics was studied by varying adsorption temperature at 25,35 and $50^{\circ} \mathrm{C}$ and keeping other experimental conditions constant.

The experimental data were used to fit the Langmuir, Freundlich, and Temkin equilibrium models. The applicability and suitability of the isotherm equation to the equilibrium data were compared by evaluating the values of the correlation coefficients, $\mathrm{R}^{2}$. The three tested models' equations are summarized in Table 1.

Kinetic models were used to investigate the controlling mechanism of sorption process of coomassie brilliant blue dye onto NSWC. Three kinetic models were applied to the present study data. These models included: pseudo-first order kinetics model, pseudo-second order kinetics model and the Elovich's kinetics model. The mechanism of adsorption was also investigated through the application of the intra-particle diffusion model. The equations of the studied models are given in Table 2. 


\section{RESULT AND DISCUSSION}

In order to investigate the texture and porosity development of the prepared adsorbent; figure 1 shows the SEM micrographs of NSWC. The scanning electron microscope (SEM) is widely used to study the morphological features and surface characteristics of the adsorbent materials. It could be seen that there are many macropores appearing on the surface of the prepared adsorbent giving an indication about its possible use as adsorbent
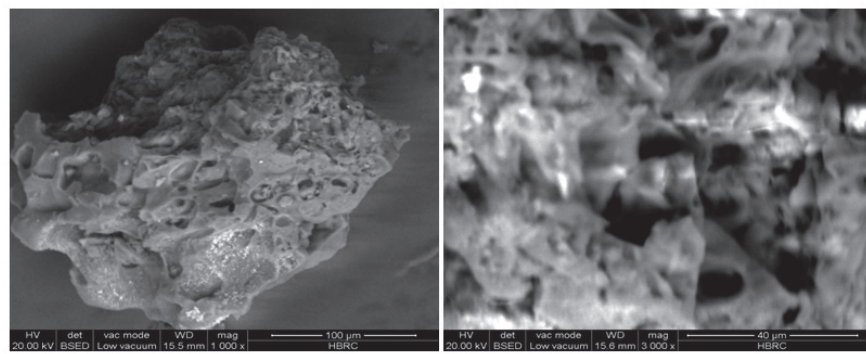

Figure1: SEM micrographs of NSWC (a) x 1000 and (b) x 3000

In the present work, information about the chemical groups on the surface of prepared adsorbent was provided by FTIR-analysis. Figure 2 depicts a strong broad band at $3420 \mathrm{~cm}^{-1}$ which is ascribed to $\mathrm{O}-\mathrm{H}$ stretching vibration in hydroxyl groups involved in hydrogen bonds ${ }^{16}$. The bands located nearly at (2923-2852) $\mathrm{cm}^{-1}$ correspond to $\mathrm{C}-\mathrm{H}$ vibrations in methyl and methylene group ${ }^{17}$ and the band at $2360 \mathrm{~cm}^{-1}$ corresponds to $v(\mathrm{C} \equiv \mathrm{C})$ vibration in alkyne group.Around $1660-1550 \mathrm{~cm}^{-1}$ is attributed to the presence of highly conjugated $\mathrm{C}-\mathrm{O}$ in a quinone/carbonyl structure ${ }^{18}$. While the appearance of two bands at $1541 \mathrm{~cm}^{-1}$ and the band at 1456 at Nigella sativa activated carbon adsorbent spectrum can be attributed to the presence of olefin $v(\mathrm{C}=\mathrm{C})$ vibrations. The band between $1450-1380 \mathrm{~cm}^{-1}$ may be due to the presence of the $\mathrm{OH}$ bending vibration and indicates the presence of phenolic group ${ }^{18}$ The broad intense and sharp band located between 1123 and $1038 \mathrm{~cm}^{-1}$ is attributable to (S-O) \& $\left(\mathrm{SO}_{2}\right)$ vibrations may be due to using $\mathrm{H}_{2} \mathrm{SO}_{4}$ as activating agent 19 . The small band at $874 \mathrm{~cm}^{-1}$ is ascribed to the $\mathrm{C}-\mathrm{H}$ out of plane bending in aromatic rings ${ }^{17}$ and finally the broad medium band at $617 \mathrm{~cm}^{-1}$ is ascribed to $(\mathrm{C}-\mathrm{S})$ band ${ }^{19}$.

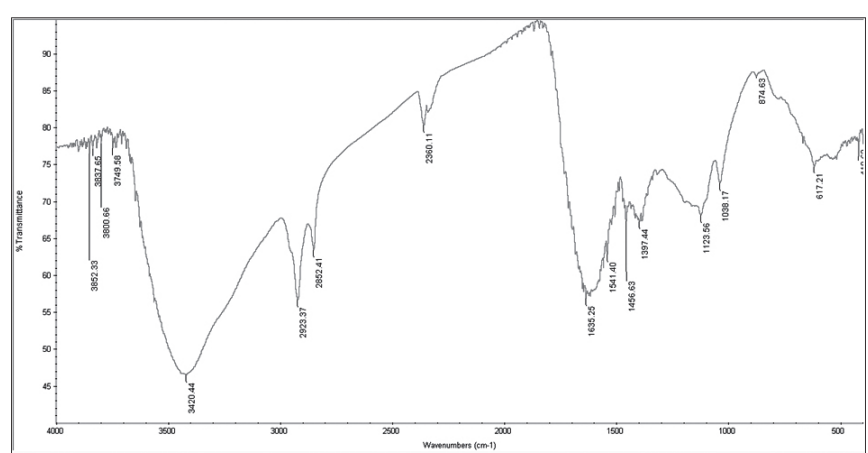

Figure 2: FTIR spectrum of NSWC.

The effect of contact time on coomassie brilliant blue removal by NSWC was studied in the range from 30 to 150 minutes in order to determine the equilibrium time of adsorption. The results are presented in Figure 3. A variation in the removal percentage of coomassie brilliant blue was generally observed in the initial adsorption period (during the first $60 \mathrm{~min}$.), then the removal started to be constant indicating that equilibrium is attained. This may due to the presence of vacant sites on the surface of adsorbent at initial stage. By the time the number of vacant sites decreased and the adsorption process became slower this due to repulsive forces between adsorbed molecules and free molecules in the solution ${ }^{20}$. As can be seen from Figure3 the removal of coomassie brilliant blue reached its equilibrium after $120 \mathrm{~min}$.

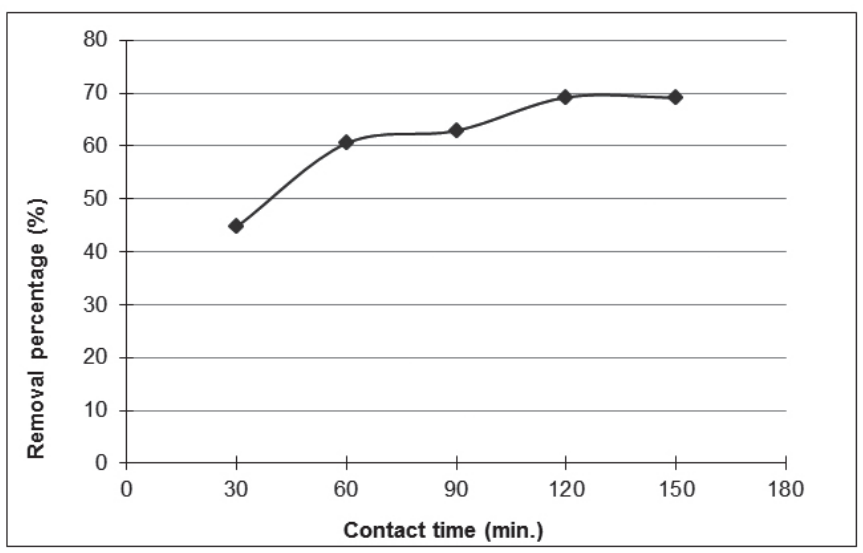

Figure 3: Removal percentage of $\mathrm{CBB}$ against time (adsorbent dose: $0.5 \mathrm{~g} / 50 \mathrm{ml}$; Coomassie brilliant blue initial concentration: $25 \mathrm{ppm} ; \mathrm{pH} 6.4$; $\mathrm{T}=310 \mathrm{~K})$.

The kinetics of coomassie brilliant blue adsorption onto NSWC was investigated by applying three kinetic models to the present study data. These models included: pseudo-first-order kinetics model, pseudo-second order kinetics model and the Elovich's kinetics model. The mechanism of adsorption was also investigated through the application of the intra particle diffusion model. The data are presented graphically in Figures 4, 5 and 6 whereas the constants calculated for each of the tested models are given in Table 3.

The data from applying the pseudo first-order equation as seen from figure 4 and Table 3, the determination coefficient $\left(\mathrm{R}^{2}\right)$ was found to be 0.92 indicating that this model may not be the best model for fitting the present study data. On the other hand, by applying the pseudo second-order adsorption kinetic rate equation (figure 5) and table 3 , high $\mathrm{R}^{2}$ value was obtained (0.99) indicating the applicability of the pseudo-second order model to fit the present data. It is clear from the data obtained after carrying out the Elovich's model and from Figure 6 and table 3, that the Elovich's model have a high determination coefficient $\left(\mathrm{R}^{2}=0.95\right)$ and may also describe the kinetics of the experimental data.

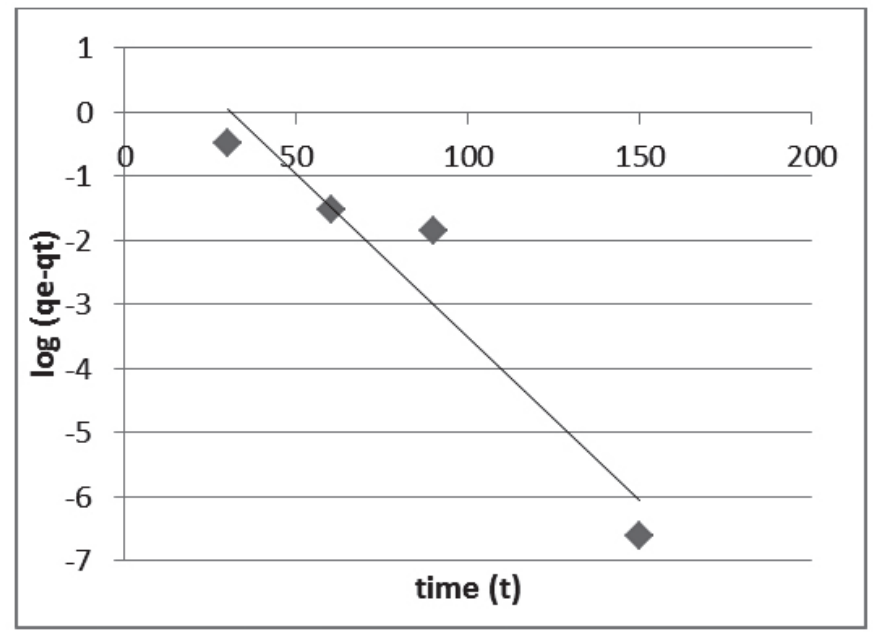

Figure 4: pseudo-first order kinetics model for CBB adsorption onto NSWC.

By comparing the data obtained from the three studied kinetic models, it can be concluded that in our study the adsorption of coomassie brilliant blue onto NSWC is best described in terms of the pseudo-second order kinetics model followed by the Elovich's model.

Several authors reported the applicability of the pseudo-second order kinetic model for coomassie brilliant blue removal onto various adsorbents including: coir pith carbon ${ }^{18}$, pinang frond based activated carbon ${ }^{21}$, watermelon rind activated carbon ${ }^{8}$, macrophyteSalvinianatans biomass ${ }^{17}$ wheat bran ${ }^{22}$. 


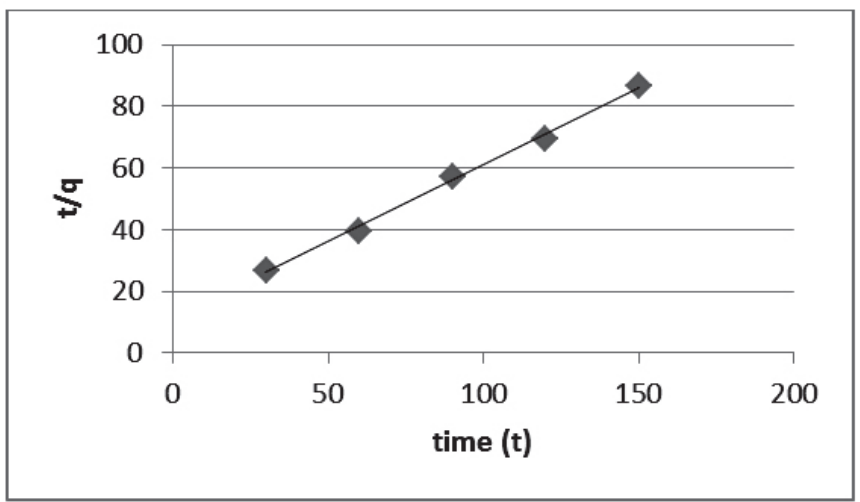

Figure 5: pseudo-second order kinetics model for CBB adsorption onto NSWC.

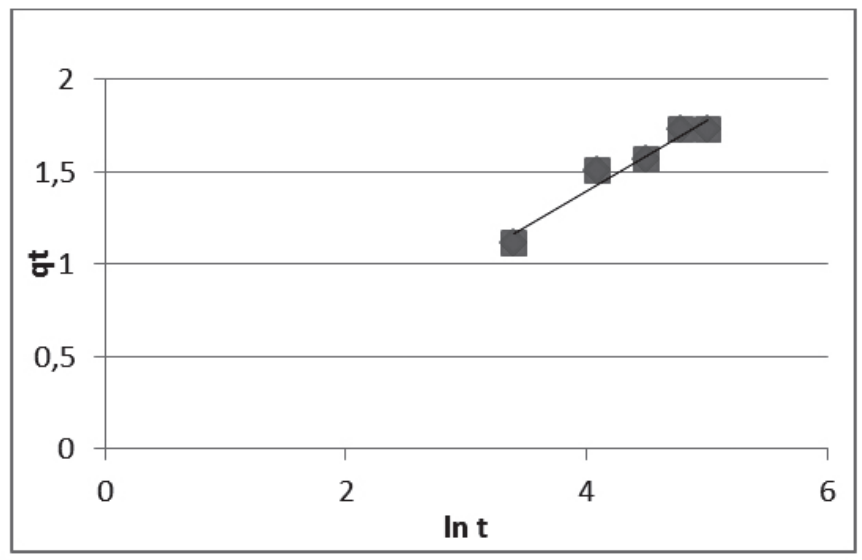

Figure 6: Elovich's kinetics model for CBB adsorption onto NSWC.

Figure7 represents the plots of $q_{t}$ versus $t^{1 / 2}$ for the removal of coomassie brilliant blue by NSWC.The plot consisted of only one linear section, presuming the presence of transitional pores in the sorbent structure. The line in the initial stage does not pass through the origin. This is indicative of some degree of boundary layer control ${ }^{23}$. The results obtained for the intraparticle diffusion model signify that there is instantaneous utilization of the most readily available adsorbing sites on the adsorbent ${ }^{18}$. Similar results were achieved by ${ }^{8}$ and. ${ }^{20}$.

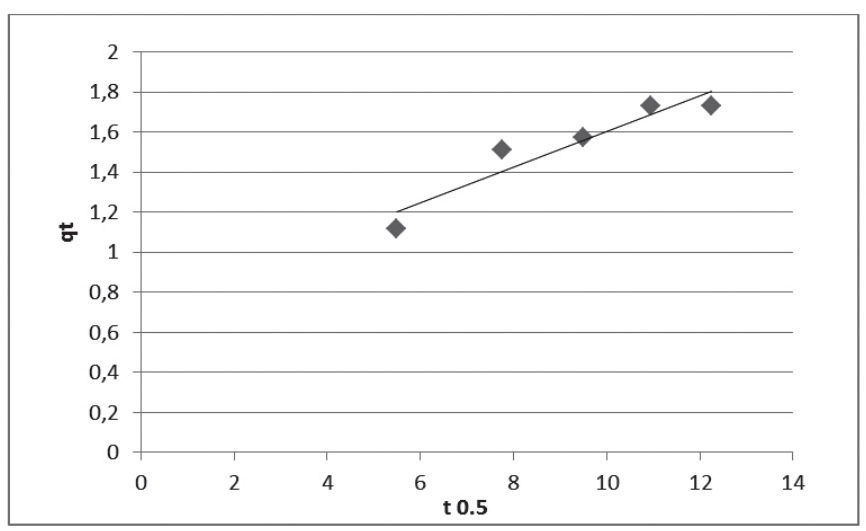

Figure 7: Intraparticle diffusion model for CBB adsorption onto NSWC.
Table 3. Kinetics model parameters for Coomassie brilliant blue adsorption by NSWC.

\begin{tabular}{|c|c|c|}
\hline Kinetic model & Parameter & Value \\
\hline \multirow{2}{*}{ Pseudo first order model } & $K 1(\mathrm{gm} / \mathrm{mg} \min )$ & 0.051 \\
& $\mathrm{R}^{2}$ & 0.915 \\
Pseudo second order model & $K_{2}(\mathrm{gm} / \mathrm{mg} \mathrm{min})$ & 0.022 \\
& $\mathrm{R}^{2}$ & 0.996 \\
& $\alpha(\mathrm{mg} / \mathrm{g} \cdot \mathrm{min}) \beta(\mathrm{g} /$ & 0.689 \\
Elovich model & $\mathrm{mg})$ & 2.604 \\
& $\mathrm{R}^{2}$ & 0.948 \\
\hline \multirow{2}{*}{ Intra particle diffusion } & $(\mathrm{gm} / \mathrm{mg} \min )$ & 0.089 \\
& $\mathrm{R}^{2}$ & 0.895 \\
\hline
\end{tabular}

The adsorption of coomassie brilliant blue by NSWC was investigated as function of initial dye concentration $(10-100 \mathrm{mg} / 1)$ and the results revealed that percentages of dye removal were found to decrease from $81 \%$ to $47.39 \%$ with an increase in the initial dye concentration from 10 to $100 \mathrm{mg} / \mathrm{l}$. in order to get a better view on the adsorption of coomassie brilliant blue by NSWC, the Langmuir, Freudlich and Temkin equilibrium models were applied to fit the experimental data. The main difference between these three models concerns the way the heat of adsorption decreases with the surface coverage ${ }^{24}$ : Langmuir assumes no decrease at all; Freundlich assumes a logarithmic decrease, while Temkin assumes a linear decrease.

The Langmuir plot of coomassie brilliant blue removal by NCWC is shown in Figure 8 and the model's calculated parameters are given in Table4. From Table4, the values of $\mathrm{R}^{2}, \mathrm{~b}$ and $\mathrm{q}_{\mathrm{m}}$ were $0.82,4.35 \mathrm{x}(\mathrm{L} / \mathrm{mg}), 14.493(\mathrm{mg} / \mathrm{g})$, respectively. It can be noticed that the Langmuir model did not show high correlation coefficient for the present data which suggests that the Langmuir model is not suitable for fitting the present data.

The Freudlich plot of CBB adsorption onto NSWC is given in Figure.9. Table 4 shows the Freundlich parameters, $\mathrm{K}_{\mathrm{F}}$ and $\mathrm{n}$, together with the correlation coefficient $\left(\mathrm{R}^{2}\right)$.

As shown in Figure9 and Table 4, the present work data were fitted well to the Freundlich model with a high correlation coefficient value $\mathrm{R}^{2}(0.994)$ the value of (n) was found to be (1.174) suggesting that the dye adsorption on NSWC is favorable 25,8 .

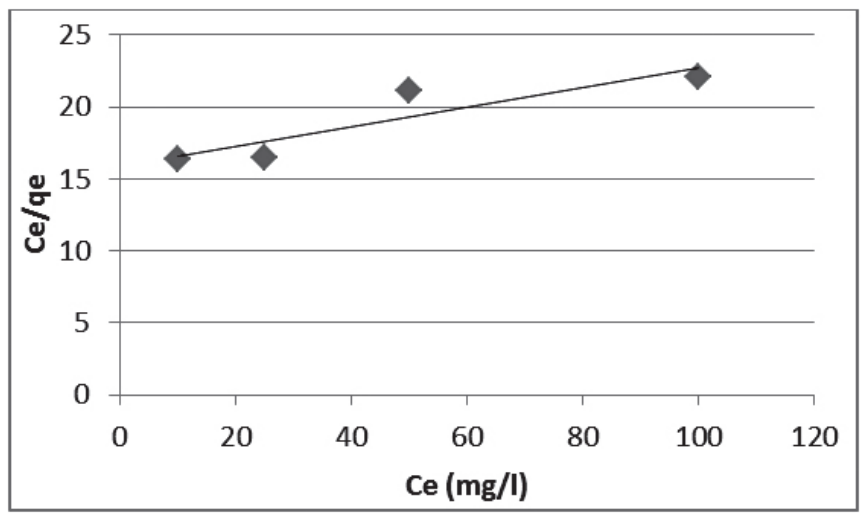

Figure 8: Langmuir plot for CBB adsorption onto NSWC. 


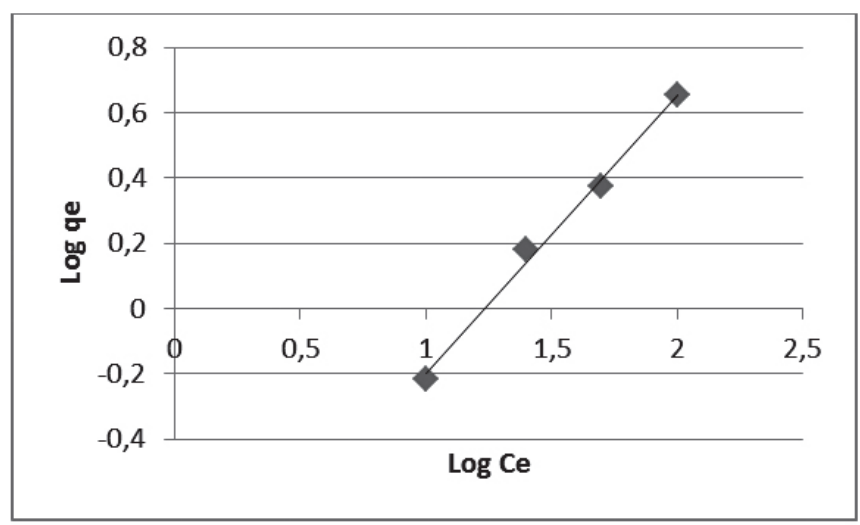

Figure 9: Freundlich plot for CBB adsorption onto NCWC.

Figure 10 gives the Temkin plot of coomassie brilliant dye removal by NSWC. The values of the Temkin constants are given in Table 4. It can be seen that the correlation $\left(\mathrm{R}^{2}=0.908\right)$ value of the model is somewhat low, indicating that Temkin isotherm did not fit well the adsorption of coomassie brilliant blue dye onto NSWC.

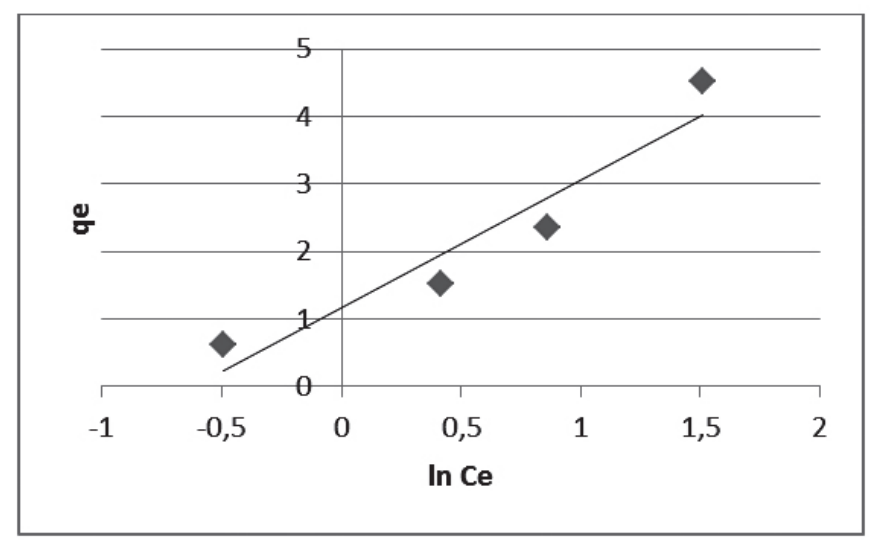

Figur10: Temkin plot for CBB adsorption onto NSWC.

Table 4: Equilibrium models and their calculated parameters.

\begin{tabular}{|l|l|l|}
\hline \multicolumn{1}{|c|}{ Equilibrium model } & \multicolumn{1}{|c|}{ parameters } & \multicolumn{1}{c|}{ values } \\
\hline Langmuir isotherm & $\mathrm{b}(\mathrm{L} / \mathrm{g})$ & $4.35 \times 10^{-3}$ \\
& $q m(\mathrm{mg} / \mathrm{g})$ & 14.493 \\
& $\mathrm{R}^{2}$ & 0.82 \\
& & \\
Freundlich isotherm & $\mathrm{K}_{\mathrm{f}}(\mathrm{L} / \mathrm{g})$ & 0.089 \\
& $\mathrm{n}$ & 1.174 \\
& $\mathrm{R}^{2}$ & 0.994 \\
Temkin isotherm & & 1.849 \\
& $A_{T}$ & 1.897 \\
& $B_{T}(\mathrm{~L} / \mathrm{g})$ & 0.908 \\
\hline
\end{tabular}

From the equilibrium studies, it can be concluded that the Freundlich model is the best model for describing the adsorption of Coomasie dye by NSWC. The applicability of the Freundlich model suggests that the adsorption surface is heterogeneous and that the adsorbent surface contains active sites with different energies ${ }^{26}$. Our results are in agreement with the results of Mafra et al., ${ }^{27}$, Ata et al., ${ }^{22}$, Dawood and Sen, ${ }^{28}$ and Abbas et al., ${ }^{29}$ who also have reported the suitability of the Freudlich model to describe the adsorption of brilliant blue dye by different adsorbents.

A comparison of our present work maximum capacity results with previously reported findings is given in table 5 .
Table 5: Comparison of obtained maximum adsorption $(q m)$ with those previously reported.

\begin{tabular}{|c|c|c|}
\hline Adsorbent material & $q m(\mathrm{mg} / \mathrm{g})$ & Reference \\
\hline Nigella sativa & 14.49 & Present work \\
\hline Wheat bran & 6.410 & 22 \\
\hline Apricot stones & 10.09 & 29 \\
\hline Peanut hull & 149.25 & 30 \\
\hline Pine cone & 49.35 & 31 \\
\hline Orange peel & 11.62 & 27 \\
\hline Citrus sinensis & 75.19 & 32 \\
\hline
\end{tabular}

In batch adsorption experiments, it is highly important to study the thermodynamic parameters such standards Gibbs free energy, $\Delta \mathrm{G}$, enthalpy, $\Delta \mathrm{H}^{\circ}$ and entropy $\Delta \mathrm{S}^{\circ}$ changes $^{33}$. The following equation was used to calculate the change in Gibb's free energy: $\Delta \mathrm{G}=-\mathrm{RT} \ln \mathrm{K}_{\mathrm{D}}$, where $\mathrm{R}$ is the universal gas constant $(8.314 \times 10-3 \mathrm{~kJ} / \mathrm{mol} \mathrm{K}), \mathrm{T}$ is the temperature $(\mathrm{K})$ and $\mathrm{K}_{\mathrm{D}}(\mathrm{qe} / \mathrm{Ce})$ is the distribution coefficient ${ }^{34}$. It is also known that $\mathrm{G}=\mathrm{H}^{\circ}-\mathrm{T} \mathrm{S} \mathrm{S}^{\circ}=-\mathrm{RT} \ln \mathrm{K}_{\mathrm{D}}$ (eq:9) and by rearrangement of this last equation, we get $\left.\ln \mathrm{K}_{\mathrm{D}}=\mathrm{S}^{\circ} / \mathrm{R}\right) \mathrm{H}^{\circ} / \mathrm{RT}$ ) (eq:10) . According to ${ }^{34}$, the enthalpy and entropy changes can be calculated from the slope and intercept of the plot of $\ln \mathrm{K}_{\mathrm{D}}$ vs. $1 / \mathrm{T}$.

In the present work Figure 11 gives the plot of $1 / \mathrm{T}$ versus $\ln \mathrm{K}_{\mathrm{D}}$ and table 6 shows the calculated values of thermodynamic parameters. From the obtained result, it can be concluded that the values of $\Delta \mathrm{G}$ at the studied temperatures were all negative. The negative values of $\Delta \mathrm{G}$ indicate the feasibility and spontaneous nature of coomassie brilliant blue dye adsorption on $\mathrm{NSWC}^{17}$. The change in enthalpy $\Delta \mathrm{H}^{\circ}$ for $\mathrm{CBB}$ adsorption process was found to be negative which indicates the exothermic nature of the adsorption at the studied temperature range $\left(25-50 \mathrm{C}^{\circ}\right)^{35}$. Also, the negative value of the adsorption entropy $\Delta \mathrm{S}^{\circ}$ demonstrates the decreased randomness at the solid-solution interface during adsorption $^{36}$.

Table6: values of the thermodynamic parameters of CBB adsorption.

\begin{tabular}{|c|c|}
\hline \multicolumn{2}{|c|}{$\mathrm{G}(\mathrm{KJ} / \mathrm{mol})$} \\
\hline $25^{\circ} \mathrm{C}$ & -4.137 \\
$35^{\circ} \mathrm{C}$ & -4.431 \\
$50^{\circ} \mathrm{C}$ & -4.763 \\
\hline $\mathrm{H}(\mathrm{KJ} / \mathrm{mol})$ & -3.264 \\
\hline $\mathrm{S}(\mathrm{J} / \mathrm{mol} . \mathrm{K})$ & -24.892 \\
\hline
\end{tabular}

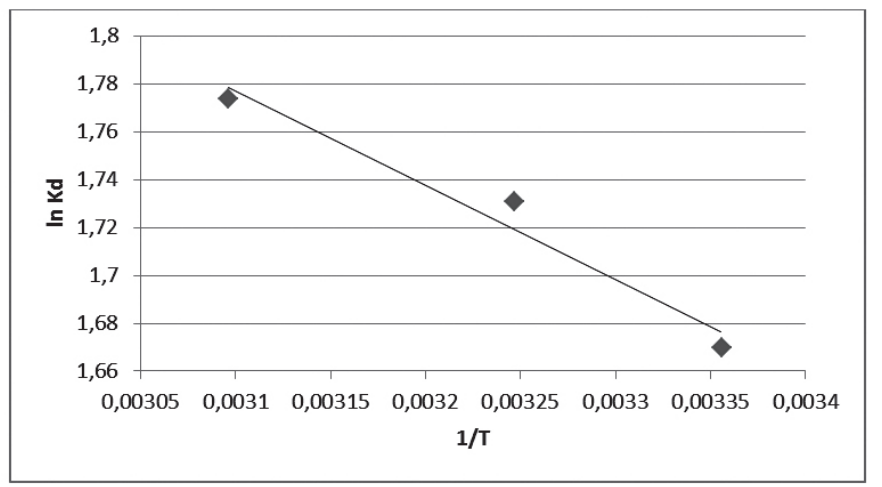

Figure11: Effect of temperature on $\mathrm{CBB}$ adsorption on NSWC.

\section{CONCLUSION}

A chemically activated carbon was successfully prepared from a cheap waste material Nigella sativa L. The prepared carbon was investigated for its possible use as adsorbent for dye removal from aqueous solutions. The 
adsorption results indicated the effectiveness of the activated carbon prepared from Nigella sativa waste for the removal of coomassie brilliant blue dye. The data modeling revealed that the adsorption process follows the pseudo second order kinetics and the Freundlich equilibrium model. The thermodynamics study indicated the spontaneity of the adsorption process. The adsorbent could be further explored and modified for the removal of other wastewater pollutants.

\section{ACKNOWLEDGMENTS}

The authors are grateful to the Faculty of Science at Cairo University, to the Agricultural Research Center and finally to the National Council for Scientific and Technological Development (CNPq, Brazil) for their support to get this work accomplished.

\section{REFERENCES}

1. Aji MM, Gutti B, Highina BK. APPLICATION OF ACTIVATED CARBON IN REMOVAL OF IRON AND MANGANESE FROM ALAU DAM WATER IN MAIDUGURI. Colomb J life Sci. 2015;17(1):35-39.

2. Poinern GEJ, Senanayake G, Shah N, Thi-Le XN, Parkinson GM, Fawcet D. Adsorption of the aurocyanide, complex on granular activated carbons derived from macadamia nut shells - A preliminary study. Miner Eng. 2011;24(15):1694-1702. doi:10.1016/j.mineng.2011.09.011.

3. Gottipati R. Preparation and Characterization of Microporous Activated Carbon from Biomass and its Application in the Removal of Chromium ( VI ) from Aqueous Phase Department of Chemical Engineering. 2012;(January).

4. Abdel-Ghani NT, El-Chaghaby G a., Zahran EM. Pentachlorophenol (PCP) adsorption from aqueous solution by activated carbons prepared from corn wastes. Int J Environ Sci Technol. 2015;12(1):211-222. doi:10.1007/s13762-013-0447-1.

5. Patil BS, Kulkarni KS. Development of High Surface Area Activated Carbon From Waste Material. Int J Adv Eng Res Stud. 2012;I(II):109113.

6. Karacan F, Ozden U, Karacan S. Optimization of manufacturing conditions for activated carbon from Turkish lignite by chemical activation using response surface methodology. Appl Therm Eng. 2007;27(7):1212-1218. doi:10.1016/j.applthermaleng.2006.02.046.

7. Alqaragully MB. Removal of Textile Dyes (Maxilon Blue, and Methyl Orange ) by Date Stones Activated Carbon. Int J Adv Res Chem Sci. 2014;1(1):48-59

8. Ahmad MA, Ahmad N, Bello OS. Removal of Remazol Brilliant Blue Reactive Dye. J Dispers Sci Technol. 2014;(September 2014):37-41. doi: 10.1080/01932691.2014.925400.

9. Rafatullah M, Sulaiman O, Hashim R, Ahmad A. Adsorption of methylene blue on low-cost adsorbents: a review. J Hazard Mater. 2010;177(1 3):70-80. doi:10.1016/j.jhazmat.2009.12.047.

10. Cimino G, Cappello RM, Caristi C, Toscano G. Characterization of carbons from olive cake by sorption of wastewater pollutants. Chemosphere. 2005;61:947-955. doi:10.1016/j.chemosphere.2005.03.042.

11. Olivares-Marín M, Fernández-González C, Macías-García a., GómezSerrano V. Preparation of activated carbon from cherry stones by physical activation in air. Influence of the chemical carbonisation with $\mathrm{H} 2 \mathrm{SO} 4 . J$ Anal Appl Pyrolysis. 2012;94:131-137. doi:10.1016/j.jaap.2011.11.019.

12. Ahmad MA, Ahmad N, Bello OS. Removal of Remazol Brilliant Blue Reactive Dye From Aqueous Solutions Using Watermelon Rinds as Adsorbent. J Dispers Sci Technol. 2014;(September 2014):37-41. doi:1 0.1080/01932691.2014.925400.

13. Lagergren SY. Zur Theorie Der Sogenannten Adsorption Gelöster Stoffe.; 1898.Availableat:http://books.google.com.eg/books/about/Zur_Theorie der_sogenannten_Adsorption_g.html?id=LPU1HQAACAAJ\&pgis=1. Accessed January 2, 2014.

14. Ho YS, McKay G. A Comparison of Chemisorption Kinetic Models Applied to Pollutant Removal on Various Sorbents. Process Saf Environ Prot. 1998;76(4):332-340. Available at: http://www.sciencedirect.com science/article/pii/S0957582098707657. Accessed January 2, 2014.

15. Abdel Salam M, Burk RC. Thermodynamics and Kinetics Studies of Pentachlorophenol Adsorption from Aqueous Solutions by Multi-Walled Carbon Nanotubes. Water, Air, Soil Pollut. 2009;210(1-4):101-111. doi:10.1007/s11270-009-0227-1.

16. Ahmad MA, Rahman NK. Equilibrium, kinetics and thermodynamic of Remazol Brilliant Orange 3R dye adsorption on coffee husk-based activated carbon. Chem Eng J. 2011;170(1):154-161. doi:10.1016/j. cej.2011.03.045

17. Pelosi BT, Lima LKS, Vieira MGA. REMOVAL OF THE SYNTHETIC DYE REMAZOL BRILLIANT BLUE R FROM TEXTILE INDUSTRY WASTEWATERS BY BIOSORPTION ON THE MACROPHYTE Salvinia natans. Brazilian J Chem Eng. 2014;31(04):1035-1045.

18. Kavitha D, Namasivayam C. Capacity of activated carbon in the removal of acid brilliant blue: Determination of equilibrium and kinetic model parameters. Chem Eng J. 2008;139(3):453-461. doi:10.1016/j. cej.2007.08.011.

19. Sathishkumar P, Arulkumar M, Palvannan T. Utilization of agroindustrial waste Jatropha curcas pods as an activated carbon for the adsorption of reactive dye Remazol Brilliant Blue R ( RBBR ). J Clean Prod. 2012;22(1):67-75. doi:10.1016/j.jclepro.2011.09.017.

20. Ratnamala GM, Shetty KV. Removal of Remazol Brilliant Blue Dye from Dye-Contaminated Water by Adsorption Using Red Mud : Equilibrium , Kinetic, and Thermodynamic Studies. Water Air Soil Pollut. 2012;223(2012):6187-6199. doi:10.1007/s11270-012-1349-4.

21. Ahmad MA, Herawan SG, Yusof AA. Equilibrium , Kinetics , and Thermodynamics of Remazol Brilliant Blue R Dye Adsorption onto Activated Carbon Prepared from Pinang Frond. ISRN Mech Eng. 2014;2014:1-7.

22. Ata S, Imran Din M, Rasool A, Qasim I, Ul Mohsin I. Removal of Coomassie Brilliant Blue on Wheat Bran As a Low-Cost Adsorbent. J Anal Methods Chem. 2012;2012:405980. doi:10.1155/2012/405980.

23. Demiral H. Adsorption of Textile Dye onto Activated Carbon Prepared from Industrial. Int Environ Appl Sci. 2008;3(5):381-389.

24. Fierro V, Torné-Fernández V, Montané D, Celzard a. Adsorption of phenol onto activated carbons having different textural and surface properties. Microporous Mesoporous Mater. 2008;111(1-3):276-284. doi:10.1016/j.micromeso.2007.08.002.

25. Ahmad a. a., Hameed BH, Aziz N. Adsorption of direct dye on palm ash: Kinetic and equilibrium modeling. J Hazard Mater. 2007;141(1):70-76. doi:10.1016/j.jhazmat.2006.06.094.

26. Hasan HA, Rozaimah S, Abdullah S, Tan N, Kamarudin SK. Isotherm equilibria of Mn $2 \mathrm{p}$ biosorption in drinking water treatment by locally isolated Bacillus species and sewage activated sludge. 2012;111:34-43. doi:10.1016/j.jenvman.2012.06.027.

27. Mafra MR, Zuim DR, Ferreira MA. ADSORPTION OF REMAZOL BRILLIANT BLUE ON AN ORANGE PEEL ADSORBENT. Brazilian $J$ Chem Eng. 2013;30(03):657-665.

28. Dawood S, Sen TK. Removal of anionic dye Congo red from aqueous solution by raw pine and acid-treated pine cone powder as adsorbent : Equilibrium , thermodynamic , kinetics , mechanism and process design. Water Res. 2012;46(6):1933-1946. doi:10.1016/j.watres.2012.01.009.

29. Abbas M, Cherfi A, Kaddour S, Aksil T. Adsorption in simple batch experiments of Coomassie blue G-250 by apricot stone activated carbon - Kinetics and isotherms modelling. Desalin Water Treat. 2015;3994(October):1-12. doi:10.1080/19443994.2015.1067871.

30. Zhong Z, Yang Q, Li X, Luo K, Liu Y, Zeng G. Preparation of peanut hull-based activated carbon by microwave-induced phosphoric acid activation and its application in Remazol Brilliant Blue $\mathrm{R}$ adsorption. Ind Crop Prod. 2012;37(1):178-185. doi:10.1016/j.indcrop.2011.12.015.

31. Unal Gec gel and Hakan Kolanc|lar*. Adsorption of Remazol Brillian Blue R on activated carbon prepared from a pine cone. Nat Prod Res Former Nat Prod Lett. 2011;(January 2014):37-41. doi:10.1080/1478641 9.2010.541878.

32. Mahwish Asgher and Haq Nawaz. REMOVAL OF REACTIVE BLUE 19 AND REACTIVE BLUE 49 TEXTILE DYES BY CITRUS WASTE BIOMASS FROM AQUEOUS SOLUTION: EQUILIBRIUM AND KINETIC STUDY. Can J Chem Eng. 2012;90(April):412-419. doi:10.1002/cjce. 20531.

33. Al-Anber ZA, Al-anber MAS, Al-anber ZA. Thermodynamics and Kinetic Studies of Iron ( III ) Adsorption by Olive Cak in a Batch System. J Mex Chem Soc. 2008;52(2):108-115.

34. Munagapati VS, Yarramuthi V, Nadavala SK, Alla SR, Abburi K. Biosorption of $\mathrm{Cu}(\mathrm{II}), \mathrm{Cd}(\mathrm{II})$ and $\mathrm{Pb}(\mathrm{II})$ by Acacia leucocephala bark powder: Kinetics, equilibrium and thermodynamics. Chem Eng J. 2010;157(2-3):357-365. doi:10.1016/j.cej.2009.11.015.

35. Hern KA, Solache M. Removal of Brilliant Blue FCF from Aqueous Solutions Using an Unmodified and Iron-Modified Bentonite and the Thermodynamic Parameters of the Process. Water Air Soil Pollut. 2013;224:1-11. doi:10.1007/s11270-013-1562-9. 
36. Ada K, Ergene A, Tan S, Yalc E. Adsorption of Remazol Brilliant Blue $\mathrm{R}$ using $\mathrm{ZnO}$ fine powder: Equilibrium, kinetic and thermodynamic modeling studies. J Hazard Mater. 2009;165(2009):637-644. doi:10.1016/j.jhazmat.2008.10.036. 